\title{
Peningkatan Literasi Kesehatan Digital Bagi Ibu-Ibu Rumah Tangga di Posyandu Flamboyan Kabupaten Bekasi
}

\author{
Rut Rismanta Silalahi, Puri Bestari Mardani, Maria Febiana Christanti \\ Universitas Pembangunan Nasional "Veteran” Jakarta \\ rut.silalahi@gmail.com
}

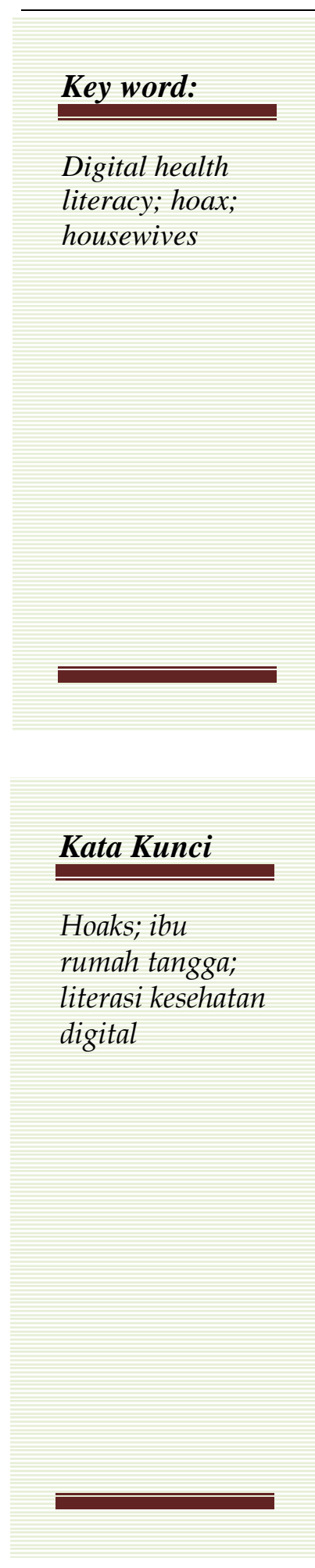

\section{Abstract}

Internet allows people to access various types of information, including health information. The problem is not all of the health information that circulating through Internet come from reliable sources. This community service intended to enhance the digital literacy on health information for the housewives in Flamboyan integrated healthcare center, Bekasi. Digital health literacy known as e-health literacy is the ability to seek, find, understand, and appraise health information from electronic sources and apply the knowledge gained to addressing or solving a health problem. These abilities are important especially for housewives since scientific research shows that there is a significant correlation between the levels of mother's literacy and the health of family. Through this community service, the housewives in Flamboyan integrated healthcare center were trained to detect hoax through a simple fact-checking process. We found out that none of the participants know how to verify the health information that they get through social media or messaging application. They were only suspicious about the information that they get if the information contains title, content, or image that does not make sense. This community service has successfully shared the effective and simple way for housewives to do fact-checking process of health information with their own smartphones.

\section{Abstrak}

Keberadaan internet membuat masyarakat bisa mengakses berbagai jenis informasi, salah satunya informasi kesehatan. Persoalannya adalah tidak semua informasi kesehatan yang beredar di internet berasal dari sumber terpercaya. Kegiatan pengabdian kepada masyarakat (PKM) ini ditujukan untuk meningkatkan literasi kesehatan digital bagi ibu-ibu rumah tangga di Posyandu Flamboyan, Kelurahan Bintara, Bekasi. Literasi kesehatan digital (Ehealth Literacy) adalah kemampuan untuk mencari, menemukan, memahami, dan menilai informasi kesehatan yang berasal dari sumber elektronik, untuk kemudian mengaplikasikannya untuk menyelesaikan masalah kesehatan. Kemampuan ini penting untuk dimiliki oleh ibu-ibu karena penelitian menunjukkan adanya korelasi antara tingkat literasi ibu dengan kesehatan keluarga. Melalui kegiatan PKM ini, ibu-ibu rumah tangga di Posyandu Flamboyan diberikan pelatihan untuk mendeteksi hoaks melalui verifikasi yang sederhana. Tim PKM menemukan bahwa semua ibu rumah tangga yang mengikuti kegiatan ini belum mengetahui cara memeriksa kebenaran informasi kesehatan yang mereka peroleh melalui media sosial ataupun aplikasi pesan singkat. Selama ini, mereka hanya menduga ada berita bohong jika informasi yang disajikan berisi judul, konten, maupun gambar yang tidak masuk akal ataupun janggal. PKM ini berhasil mengajarkan cara yang efektif dan juga mudah dilakukan oleh ibuibu rumah tangga untuk menangkal hoaks kesehatan lewat ponsel mereka. 


\section{PENDAHULUAN}

Arus informasi mengalir sangat deras di era digital ini. Berbagai jenis informasi begitu mudah diakses, mulai dari informasi politik, hiburan, ekonomi, hingga kesehatan. Informasi yang akurat bercampur dengan informasi yang tidak akurat, berita bohong dan menyesatkan (hoaks). Hoaks kini sudah mewabah dan menjadi masalah besar bagi Indonesia. Menurut survey yang dilakukan oleh Masyarakat Telematika Indonesia, ada tiga jenis hoaks yang paling banyak diterima masyarakat adalah hoaks terkait sosial politik (pilkada, pemerintah) $91.80 \%$, SARA $88.60 \%$, dan kesehatan 41.20\% (Masyarakat Telematika Indonesia, 2017). Dalam kegiatan Pengabdian Kepada Masyarakat (PKM) ini, kami khusus mencermati hoaks kesehatan. Detik Health melansir 10 Hoaks kesehatan yang sering beredar di Whatsapp dan Facebook, antara lain: main ponsel di tempat gelap sebabkan tumor mata; MSG berbahaya untuk otak; mie instan sebabkan kanker; tusukan jarum untuk mengatasi stroke; dan vaksin HPV memicu menopause dini (Anwar, 2019). Informasi-informasi yang disebutkan itu kerap kali dikonsumsi oleh masyarakat tanpa ada upaya untuk mengecek terlebih dahulu kebenarannya. Kalaupun ada pihak yang sudah membantah hoaks-hoaks yang beredar, klarifikasinya tidak menyebar secepat hoaksnya. Hal ini yang menyebabkan hoaks semakin merajalela ("Hoaks di Twitter Lebih Gampang Menyebar dari Klarifikasi. Mengapa?," 2018)

Hoaks kesehatan biasanya dikemas sedemikian rupa sehingga tampak valid. Caranya adalah dengan menyertakan klaimklaim yang tampak ilmiah dan istilah-istilah rumit yang terdengar keren oleh orang awam, padahal sebenarnya tidak relevan apalagi valid. Hal ini seperti psudoscience atau ilmu semu, yaitu pengetahuan atau keyakinan yang diklaim sebagai ilmiah padahal tidak diperoleh melalui metode ilmiah. Hoaks kesehatan ini dapat menimbulkan keresahan di masyarakat, terutama bagi yang tidak melek sains dan literasi media digital. Sayangnya, penyebar hoaks itu kebanyakan adalah ibu-ibu rumah tangga ("Miris, Penyebar Hoax Mayoritas Ibu-Ibu," 2018). Ibu-ibu seperti ini biasanya tidak kritis terhadap informasi yang mereka terima, sehingga mereka mudah mempercayai apa pun yang ada di internet dan media sosial. Apalagi jika beritanya heboh dan bersifat menakut-nakuti, mereka akan menyebarkannya dengan cepat. Mungkin saja alasannya adalah mereka khawatir jika informasi tersebut ternyata benar maka bisa membahayakan anggota keluarga serta orang-orang terdekatnya.

Peran Ibu dalam mengurus kesehatan keluarganya sangatlah besar (PY, 
DA, \& Galal, 2005). Tentu sangat berbahaya bila ibu-ibu tidak bisa mengenali mana informasi kesehatan yang valid dan yang tidak, kemudian dengan sembarangan menerapkannya bagi anggota keluarganya. Oleh karena itu, kegiatan PKM kami menyasar ibu-ibu rumah tangga. Mitra yang kami pilih adalah ibu-ibu rumah tangga di Posyandu Flamboyan Kelurahan Bintara Jaya Bekasi Barat.

Sebelum melakukan kegiatan PKM, kami melakukan analisis kebutuhan dengan cara menyebarkan kuesioner dan mewawancarai para pengurus dan kader Posyandu Flamboyan. Dari kuesioner yang telah diisi, kami menemukan bahwa semua responden pernah mendapatkan informasi kesehaditan (yang ternyata adalah hoaks) melalui media sosial dan aplikasi pesan singkat (Whatsapp). Beberapa respon mereka terhadap informasi tersebut adalah meneruskannya ke anggota keluarga dan grup Whatsapp lainnya, bertanya ke anaknya tentang kebenaran informasi tersebut, atau mendiamkannya. Semua responden mengakui bahwa mereka tidak tahu cara memeriksa (secara mandiri) kebenaran informasi kesehatan yang mereka peroleh di media sosial atau aplikasi pesan singkat. Dari hasil analisis kebutuhan ini, kami menilai bahwa ibu-ibu rumah tangga di area sekitar posyandu Flamboyan ini membutuhkan edukasi tentang literasi kesehatan digital, termasuk di dalamnya kemampuan untuk memverifikasi hoaks kesehatan dengan menggunakan gawai (ponsel pintar) yang mereka miliki. Tujuannya adalah agar ibu-ibu bisa lebih kritis saat mengonsumsi informasi kesehatan digital, mampu memilah informasi kesehatan yang valid dan tidak, sehingga pada akhirnya peran mereka sebagai manager kesehatan keluarga bisa lebih optimal

\section{METODE PEMECAHAN MASALAH}

Kegiatan PKM ini menggunakan berbagai metode untuk menunjang proses belajar yang efektif.

1. Metode pertama yang digunakan adalah seminar interaktif. Metode ini digunakan untuk menjelaskan situasi media sosial dan aplikasi pesan singkat yang penuh dengan hoaks. Peserta diberi tahu tentang definisi dan jenisjenis hoaks (termasuk hoaks kesehatan), alasan orang membuat hoaks, serta dampak nyata dari bahayanya hoaks. Peserta juga disadarkan bahwa siapa saja bisa tertipu oleh hoaks, tanpa pandang jenis kelamin, tingkat pendidikan, latar belakang ekonomi, agama, sosial budaya. Bahkan, orang yang berpendidikan tinggi pun rentan tertipu oleh hoaks. 
2. Metode kedua adalah pelatihan. Peserta secara langsung dilatih untuk dapat mendeteksi hoaks kesehatan dan melakukan verifikasi secara sederhana. Beberapa cara yang telah diajarkan kepada para peserta antara lain mengecek informasi di mesin pencari Google atau langsung ke situs ataupun akun yang memang dikhususkan untuk mengklarifikasi hoaks, seperti: www.turnbackhoax.id,

www.cekfakta.com, www.stophoax.id, akun grup di Facebook (Forum Anti Fitnah, Hasut, dan Hoax), akun instagram pembantah hoaks yang dibuat oleh Kominfo, yaitu Miss Lambe Hoaks. Diperlukan kejelian untuk mencari kata kunci yang tepat dan juga ketekunan dalam membaca hasil dari pencarian tersebut. Para peserta dihimbau untuk tidak malas membaca, karena sebetulnya kemalasan membaca inilah yang dimanfaatkan oleh para pembuat hoaks untuk menyebarkan kebohongan atau kesesatan. Cara kedua adalah mengecek keaslian video di mesin pencari Google dan Youtube. Tim PKM memberikan contoh hoaks video yang beredar tentang sapi hasil persilangan dengan babi, lalu membantu peserta untuk mencari tahu apakah video tersebut hoaks atau bukan. Ternyata, videonya asli, namun narasinya salah. Hal seperti ini yang perlu diwaspadai oleh para peserta, karena jika mereka tidak memeriksa kecocokan video dan narasi, mereka bisa saja mempercayai bahwa ada sapi hasil persilangan dengan babi. Cara ketiga adalah mengecek keaslian gambar/foto dengan Google reverse image. Untuk melakukannya, para peserta membutuhkan ponsel pintar dengan sistem operasi Android. Bagi peserta yang menggunakan ponsel pintar dengan iOS perlu mengunduh aplikasi Google Chrome. Tim PKM mengirimkan sebuah gambar ke group Whatsapp para peserta untuk dicek apakah gambar tersebut hoaks atau bukan. Gambar yang dikirim adalah gambar seorang perempuan sedang membuat bakso dari daging tikus. Pertama-tama, peserta harus membuka Google Images dalam versi desktop (bukan versi mobile). Caranya adalah klik tiga titik di kanan atas, lalu cari dan klik dekstop site (Gambar 1). Tampilan Google Images dalam versi dekstop dapat dilihat di Gambar 2. Selanjutnya, pilih gambar kamera dan akan muncul Search by Image. Di situ terdapat dua pilihan: Paste Image URL (masukkan URL gambar) atau Upload an Image (Unggah gambar yang sudah tersimpan di gawai). Peserta kemudian diminta 
untuk memilih upload an image, karena tim PKM sudah mengirimkan gambar ke grup Whatsapp peserta. Gambar yang hendak diunggah dapat dicari di lokasi penyimpanan gambar di masing- masing ponsel pintar milik peserta. Setelah gambar tersebut diunggah, Google Image pun mencari gambargambar serupa atau relevan yang beredar di internet (Gambar 3)

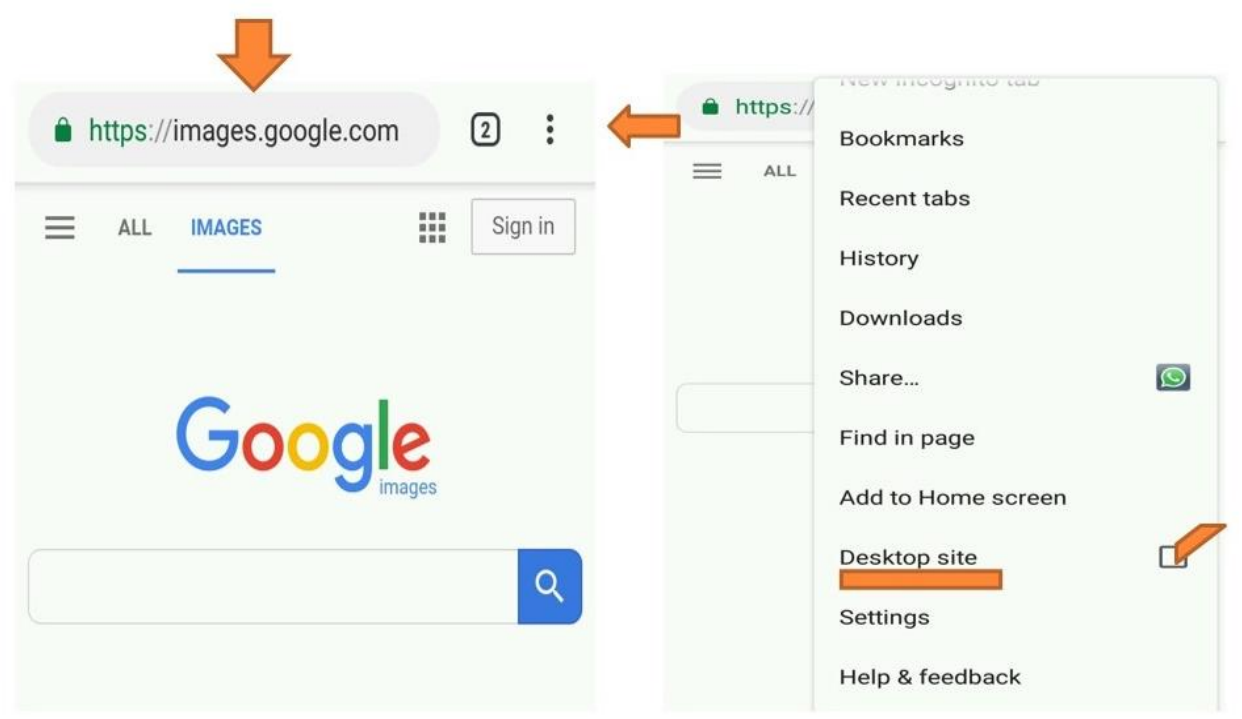

Gambar 1. Cara mengubah versi mobile menjadi versi dekstop

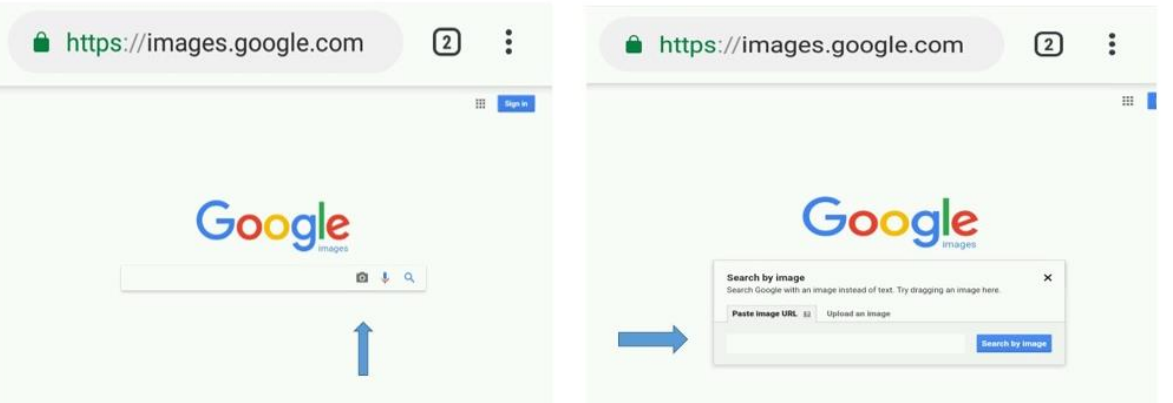

Gambar 2. Cara mencari gambar di Google Images 

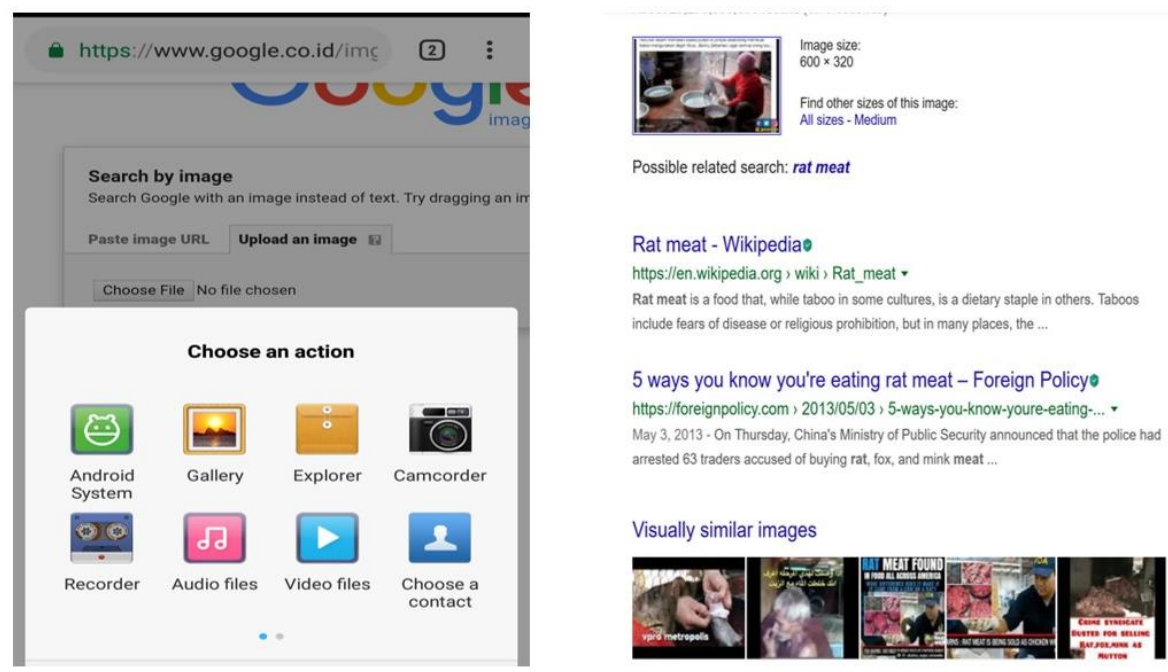

Gambar 3. Hasil pencarian dengan Google reverse image

Langkah selanjutnya setelah memperoleh hasil pencarian dari Google adalah membacanya dan menarik kesimpulan apakah gambar tersebut benar atau tidak.

3. Metode ketiga adalah diskusi. Metode ini digunakan untuk memberikan kesempatan kepada peserta pelatihan ini untuk mengetahui lebih lanjut mengenai penyebaran hoaks, khususnya hoaks kesehatan, melalui sesi tanya-jawab serta sharing pengalaman masing-masing saat menerima dan merespon hoaks. Metode keempat adalah metode pembelajaran reflektif. Metode ini memberikan kesempatan kepada peserta untuk mengecek pemahaman mereka tentang hoaks setelah mengikuti sesi dari tim PKM, lalu apa yang akan mereka lakukan selanjutnya (dituangkan dalam bentuk komitmen pribadi) agar lebih kritis terhadap informasi-informasi (khususnya kesehatan) yang mereka terima melalui media sosial ataupun aplikasi pesan singkat. Peserta menuliskan apa yang mereka pelajari dan komitmen pribadi mereka di postit.

\section{HASIL}

Kegiatan PKM ini diikuti oleh 30 ibuibu rumah tangga dengan rentang usia dari 30-60 tahun. Sebagian besar peserta yang ikut adalah pengurus dan kader dari Posyandu Flamboyan. Secara umum, kegiatannya berjalan dengan lancar, meskipun ada beberapa kendala teknis yang ditemui, seperti tidak adanya jaringan internet (Wi-fi) yang membuat peserta harus menggunakan paket data masing-masing dan sinyalnya tidak semua kuat. Hal ini agak 
menghambat proses latihan untuk mengecek hoaksnya. Tingkat keterampilan menggunakan gawai yang beragam juga membuat proses latihan memakan waktu lebih lama dari yang telah dialokasikan.

Berdasarkan obervasi yang dilakukan tim PKM, peserta banyak mencatat materi yang disampaikan. Mereka tidak banyak bertanya, tetapi mau bercerita tentang informasi-informasi yang sering mereka terima melalui Whatsapp. Setelah diajari cara mengecek keaslian video ataupun gambar, beberapa peserta berpendapat bahwa prosesnya ternyata tidak sesederhana yang mereka bayangkan. Mereka mengira bahwa cara yang diajarkan bisa langsung memberi tahu apakah informasi tersebut hoaks atau bukan. Namun ternyata mereka masih harus membaca dengan cermat hasil pencarian dari Google, karena seringkali yang ditampilkan oleh Google bukan langsung klarifikasi hoaksnya, tetapi justru situs-situs yang menyebarkan hoaksnya. Hal ini terjadi karena penyebaran hoaks sudah begitu luas, sehingga hasil yang muncul pertama di pencarian Google adalah hoaksnya itu sendiri. Menanggapi hal ini, tim PKM menjelaskan bahwa membaca adalah salah satu aspek penting dalam literasi digital. Namun, orang Indonesia termasuk malas membaca. Hasil survey tahun 2016 yang dilakukan oleh Central Connecticut State University menyatakan bahwa Indonesia menempati urutan ke 60 dari 61 negara yang disurvey. Indonesia hanya satu tingkat di atas negara Botswana (Gunawan, 2016). Tentu ini bukanlah hal yang membanggakan. Oleh karena itu, tim PKM mendorong para peserta untuk mau lebih rajin membaca, agar tidak mudah juga tertipu oleh hoaks.

Di akhir kegiatan, peserta diminta untuk menuliskan hal-hal baru yang mereka pelajari dan komitmen pribadi mereka ke depannya. Berikut ini rangkuman respon peserta terkait dengan hal-hal baru yang dipelajari:

- Hoaks adalah berita bohong

- Siapa saja tertipu oleh hoaks

- Hoaks banyak macamnya

- Cara mengecek hoaks lewat gadget

- Orang bisa dapat banyak uang dengan menyebarkan hoaks

- Hoaks sangat berbahaya

- Situs-situs yang bisa dibuka kalau mau mengecek soal hoaks

Selanjutnya adalah rangkuman komitmen pribadi peserta untuk dilakukan setelah kegiatan, yaitu:

- Tidak lagi sembarangan menyebarkan informasi yang belum dicek kebenarannya (tahan jempolnya)

- Ternyata mendiamkan hoaks itu tidak baik, kita perlu ikut aktif mengklarifikasi hoaks tersebut 
- Hati-hati terhadap berita yang judulnya sensasional

- Mau baca secara lengkap, jangan cuma baca judul beritanya.

\section{PEMBAHASAN}

Dalam perkembangan era digital, terdapat tantangan serius, yaitu kesenjangan digital/digital divide (Riggins \& Dewan, 2005). Kesenjangan digital ini dibagi menjadi dua, yaitu kesenjangan di sisi akses terhadap teknologi informasi komunikasi (TIK) (lapis pertama) dan kesenjangan di kemampuan menggunakan TIK (lapis kedua). Peserta kegiatan PKM ini adalah ibu-ibu rumah tangga yang memiliki ponsel pintar dan akses internet. Artinya, tidak ada masalah di sisi akses, meskipun ada beberapa peserta yang sinyal ponselnya tidak begitu baik.

Meski demikian, dari hasil kuesioner yang dibagikan di awal kegiatan, para peserta mengakui kalau mereka tidak tahu cara memverifikasi informasi (termasuk informasi kesehatan) yang mereka peroleh di media sosial ataupun aplikasi pesan singkat. Saat kegiatan PKM berlangsung, tingkat keterampilan para peserta dalam menggunakan ponsel pintar mereka juga beragam. Hal ini membuat proses latihan mengecek fakta memakan waktu lebih lama dari yang telah dialokasikan. Kondisi ini masuk kategori kesejangan digital lapis kedua (second order digital divide), yaitu kesenjangan di kemampuan menggunakan media digital.

Keterampilan/kemampuan yang dimaksud dalam literasi media digital mencakup 5 hal (Hobbs \& Moore, 2016) yaitu:

1. Kemampuan untuk mengakses media dan perangkat teknologi yang tepat serta membagikan informasi yang relevan kepada orang lain.

2. Kemampuan untuk memahami pesan dan menggunakan daya pikir kritis untuk menganalisis kualitas, kebenaran, kredibilitas, dan sudut pandang pesan, sambil mempertimbangkan dampak dari pesan tersebut.

3. Kemampuan untuk menciptakan pesan yang kreatif, dengan kesadaran penuh akan tujuan penyampaian pesannya, siapa khalayak yang dituju, serta teknik penyampaian yang tepat.

4. Kemampuan untuk merefleksikan tanggung jawab sosial dan prinsipprinsip etika dalam berkomunikasi

5. Kemampuan untuk bertindak secara individual maupun bekerja secara kolaboratif dengan orang lain untuk membagikan informasi dan memecahkan masalah dalam ruang lingkup keluarga, lingkungan kerja, komunitas, dan masyarakat secara umum. 
Sementara itu, literasi media digital di bidang kesehatan disebut dengan literasi kesehatan digital (E-health Literacy), yaitu kemampuan untuk mencari, menemukan, memahami dan menilai informasi kesehatan yang berasal dari sumber elektronik untuk kemudian mengaplikasikannya untuk menyelesaikan masalah-masalah kesehatan (Norman \& Skinner, 2006). Keterbatasan waktu untuk melakukan kegiatan PKM ini membuat tim PKM memfokuskan pada materi yang dapat meningkatkan kemampuan ibu-ibu rumah tangga untuk memahami, menilai, menganalisis kebenaran informasi kesehatan yang mereka peroleh di media sosial atau aplikasi pesan singkat.

Selain tantangan dari segi waktu, ada pula tantangan dari sisi peserta. Mereka mengungkapkan 'keengganan' untuk membaca secara cermat penjelasan dari hasil pencarian Google. Mereka mengira bahwa cara yang tim PKM berikan akan langsung memberi tahu mereka apakah sebuah informasi itu hoaks atau bukan. Kenyataan ini menunjukkan bahwa memang ada permasalahan di level literasi tradisional orang Indonesia, yaitu membaca. Minat baca yang rendah menjadi salah satu penyebab rendahnya literasi media digital, karena menurut (Jenkins, Clinton, Purushotma, Robison, \& Weigel, 2009), literasi media digital merupakan keterampilan sosial dan kultural yang dikembangkan lewat jaringan dan dilandasi oleh literasi tradisional (menulis dan membaca), kemampuan meneliti, dan berpikir kritis di media. Jadi, upaya untuk meningkatkan literasi media digital di Indonesia tidak bisa lepas dari upaya untuk meningkatkan minat baca masyarakatnya.

\section{KESIMPULAN}

Kesimpulan kegiatan PKM yang dilaksanakan, literasi kesehatan digital ibuibu rumah tangga masih rendah, terutama kemampuan untuk mengevaluasi kebenaran informasi kesehatan yang beredar di media sosial dan aplikasi pesan singkat. Selain itu, cara-cara yang diajarkan kepada peserta untuk mengecek keaslian foto, video, dan kebenaran informasi dengan mesin pencari Google, tidak akan ada artinya jika para peserta tetap malas membaca. Hasil pencarian Google tersebut tetap harus dibaca dan ditelaah agar kita bisa memperoleh kesimpulan yang tepat apakah sebuah informasi itu hoaks atau bukan.

Dari segi teknis, ketersediaan jaringan internet yang memadai juga penting untuk disediakan agar proses latihan mengecek informasi, foto, dan video tidak terhambat. Jika audiensnya lebih banyak, diperlukan jumlah fasilitator yang lebih banyak juga agar bisa mendampingi mereka dalam berlatih memverifikasi hoaks. 


\section{SARAN}

(Suwana \& Lily, 2017) mengungkapkan bahwa ibu-ibu merupakan salah satu kelompok sosial yang menjadi target untuk program literasi digital di Indonesia, karena ibu adalah pendukung utama kesejahteraan keluarga, dan mereka berperan penting dalam mempersiapkan anak-anak mereka menjadi generasi digital yang lebih baik dan kompeten. Oleh karena itu, kegiatan-kegiatan seperti ini dapat dilakukan lebih banyak dengan audiens ibuibu rumah tangga dari kelas sosial yang lebih beragam.

\section{DAFTAR PUSTAKA}

Anwar, F. (2019, February 20). 10 Hoax Kesehatan Yang Sering Beredar di Whatsapp dan Facebook. Detik Health. Retrieved from https://health.detik.com/beritadetikhealth/d-4436167/10-hoaxkesehatan-yang-sering-beredar-diwhatsapp-danfacebook?_ga=2.78427543.26905460 7.1560313625244677015.1560313625

Gunawan, S. A. (2016, March 12). Indonesia second least literate of 61 nations. Jakarta Post. Retrieved from https://www.thejakartapost.com/news/ 2016/03/12/indonesia-second-least- literate-61-nations.html

Hoaks di Twitter Lebih Gampang Menyebar dari Klarifikasi. Mengapa? (2018). Kompas.Com. Retrieved from https://tekno.kompas.com/read/2018/0 3/14/08040367/hoaks-di-twitter-lebihgampang-menyebar-dari-klarifikasimengapa?page $=$ all

Hobbs, R., \& Moore, D. (2016). Digital and Media Literacy. In Discovering Media Literacy: Teaching Digital Media and Popular Culture in Elementary School. https://doi.org/10.4135/978150633544 $5 . \mathrm{n} 2$

Jenkins, H., Clinton, K., Purushotma, R., Robison, A. J., \& Weigel, M. (2009). JENKINS_Confronting the Challenges $\begin{array}{lll}. P D F & 4,\end{array}$ https://doi.org/10.1016/B978-0-12801867-5.00008-2

Masyarakat Telematika Indonesia. (2017). Hasil Survey Mastel Tentang Wabah Hoax Nasional. Retrieved from https://mastel.id/hasil-survey-wabahhoax-nasional-2017/

Miris, Penyebar Hoax Mayoritas Ibu-Ibu. (2018, November 12). Jawa Pos. Retrieved from https://www.jawapos.com/hoax-ataubukan/12/11/2018/miris-penyebarhoax-mayoritas-ibu-ibu/

Norman, C. D., \& Skinner, H. A. (2006). eHealth literacy: Essential skills for 
consumer health in a networked world.

Journal of Medical Internet Research,

$8(2)$,

$1-10$.

https://doi.org/10.2196/jmir.8.2.e9

PY, G., DA, G., \& Galal, O. (2005). Women and family health: the role of mothers in promoting family and child health. International Journal of Global Health \& Health Disparities, 4(1), 30-42. Retrieved from http://search.ebscohost.com/login.aspx ?direct $=$ true $\& \mathrm{db}=\operatorname{cin} 20 \& \mathrm{AN}=106547$ $665 \&$ site $=$ ehost-live

Riggins, F., \& Dewan, S. (2005). The Digital Divide: Current and Future Research Directions. Journal of the Association for Information Systems, 6(12), 298-337. https://doi.org/10.17705/1jais.00074

Suwana, F., \& Lily. (2017). Empowering Indonesian women through building digital media literacy. Kasetsart Journal of Social Sciences, 38(3), 212217.

https://doi.org/10.1016/j.kjss.2016.10.

004 